BRINGING THE HEART AND SOUL BACK IN: COLLABORATIVE INQUIRY AND THE DBA

\author{
Dr Amanda Hay \\ Nottingham Business School \\ Nottingham Trent University \\ 50 Shakespeare Street \\ Nottingham NG1 4FQ \\ TEL: +44 (0) 1158486118 \\ amanda.hay@ntu.ac.uk \\ Professor Dalvir Samra-Fredericks \\ Nottingham Business School \\ Nottingham Trent University \\ 50 Shakespeare Street \\ Nottingham NG1 4FQ \\ TEL: +44 (0)115 8482078 \\ dalvir.samra@ntu.ac.uk
}




\section{BRINGING THE HEART AND SOUL BACK IN: COLLABORATIVE INQUIRY}

\section{AND THE DBA}

Waddock and Lozano (2013) propose that there is an urgent need to bring the 'heart and soul' back into management education. Indeed, its absence has also been implicated in the plethora of recent scandals and the global financial crisis. We suggest that, in part, such issues are attributable to a continued over reliance on a scientific and detached form of knowing which displaces particular 'human characteristics' and in so doing, downplays our inherent connections to others. In contrast, we identify the importance of embracing a supplementary form of knowing- collaborative inquiry which potentially restores our connections to others in ways which provide opportunities for a more heartfelt and soulful management practice. Specifically, we extend Van de Ven and Johnson's (2006) notion of collaborative inquiry to consider how it is mobilized in the context of a UK DBA program and in turn examine the impact this move accomplishes. Drawing upon a detailed analysis of twenty students' reflective journals, we illustrate the ways in which they develop a form of empathy. Crucially, we found that this was one important means for (re)-connecting to others and in ways which begin to bring in a sense of heart and soul back into management education. 
Waddock and Lozano (2013) propose that there is an urgent need to bring the 'heart and soul' back into management education. Further, its absence has also been implicated in the plethora of relatively recent scandals and the global financial crisis (Nonaka, Chia, Holt, \& Peltokorpi, 2014; Ghoshal, 2005; Khurana, 2010). We suggest that, in part, such issues are attributable to management education's continued over reliance on a scientific and detached knowing which tends to displace 'human characteristics' encompassing facets of heart and soul and in so doing, downplays our inherent connections to others (Yanow, 2009). Instead, we identify the importance of embracing a supplementary form of knowing - collaborative inquiry which develops a form of empathy which potentially restores our connections to others, and which consequently provides opportunities for a more heartfelt and soulful management practice which we define shortly.

Specifically, we suggest that Van de Ven and Johnson's (2006) notion of 'engaged scholarship' which has collaborative forms of inquiry at its centre offers educators one tangible starting point for enhancing a capacity for a sense of heart and soul. Yet, their framework has been confined to a research context with its promise for facilitating learning left unexplored. Here, we suggest that DBA (Doctor of Business Administration) programs which, to date, have received scant empirical attention (Banerjee \& Morley, 2013) provide one important learning site where discussions of collaborative inquiry are especially apposite since they bring together academics and highly experienced senior practitioners-our studentswith an aim of developing 'researching professionals'. We elaborate on this claim by drawing on our involvement with a particular UK DBA program to answer two related research questions 1) how is collaborative inquiry mobilized in a learning context, and 2) what impact does this accomplish? To understand more local, practical and nuanced forms of collaborative inquiry and its impact, we analyzed twenty reflective journals submitted by students as part of their program assessment. 
We offer two related contributions. First, we extend Van de Ven and Johnson's (2006) notion of collaborative inquiry to consider how it is mobilized in a learning context. Second, we consider the impact of this form of inquiry through our analysis of DBA students' reflective journals. We illustrate the ways in which collaborative inquiry as mobilized here, and as something captured and described by student practitioners themselves, created impact which extended beyond rational and instrumental concerns of advancing research knowledge (Van de Ven \& Johnson, 2006) to one which developed a form of empathy. Crucially, as we will see, this is established as one important means for (re)-connecting to others and ultimately bringing a sense of heart and soul back into management education. This may potentially lessen future business scandals and crises too.

Our article is structured as follows. We begin by considering two forms of knowing in management education - detached knowing and collaborative knowing and outline how the latter provides opportunities for developing a form of empathy which potentially brings a specific notion of heart and soul back in. Having described Van de Ven and Johnson's (2006) particular form of collaborative inquiry, we consider how this is also relevant to the context of a UK DBA program. We next describe our diary method as a means to understand how collaborative inquiry is mobilized in this context as well as the impact it accomplishes. Our analysis of students' diaries is then presented followed by our discussion and implications for management educators.

\section{THE ELEVATION OF DETACHED KNOWING}

Management education has continued to be the subject of much critique over recent years (Brocklehurst, Sturdy, Winstanley, \& Driver, 2007; Chia \& Holt, 2008; Datar, Garvin, \& Cullen, 2011; Holtom \& Dierdrorff, 2013; Mintzberg, 2004; Pfeffer \& Fong, 2002; Starkey, Hatchuel, \& Tempest, 2004). Central to this critique has been the suggestion that a continued 
over reliance on scientific principles has developed a narrow and overly analytical form of management education which elevates a particular way of knowing (Bennis \& O’ Toole, 2005; Chia \& Holt, 2008; Irgens, 2014; Saggurthi \& Thakur, 2016; Yanow, 2009). Often, informed by a realist philosophy, management education has tended to privilege a stance which conceptualizes the world as 'out there': as an independent and fixed reality waiting to be discovered and acted upon by the detached observer. Critically, in this scheme, 'the human characteristics' of the observer and the observed are displaced (Yanow, 2009). This observer is also one who relies upon “"objective' procedures and methods through which certain, universal knowledge is produced" (p.583). Accordingly, the observed are also typically positioned as objects to be manipulated rather than as persons to be engaged with (see Yanow, 2009: 588).

Ultimately, it is claimed that this stance gives rise to the enactment of a form of self-reliant, self-assured and dispassionate knowing (Chia \& Holt, 2008). One relevant outcome for this paper is deemed to be forms of management education which distort those subjected to it into “critters with lopsided brains, icy hearts and shrunken souls" (Leavitt, 1989:39). Potentially too, this cultivation of cold, detached and overly self-assured analysts with an apparent lack of concern for their impact on others, has played its part in the plethora of recent scandals and the financial crisis (Nonaka et al, 2014; Ghoshal, 2005; Khurana 2010). Given this, there have been renewed calls for management education to enhance a capacity for "heart and soul" (Waddock \& Lozano, 2013). We suggest that embracing additional forms of knowing which re-establish our connectedness to others provides one important starting point. To be clear, we are not suggesting the replacement of one form of knowing with another, but rather the importance of embracing both forms of knowing. We outline our contrasting philosophical stance next which pivots on the notion of connectedness, before offering our conceptualization of 'heart and soul'. 


\section{COLLABORATIVE KNOWING}

We suggest that understanding and developing a capacity for heart and soul is advanced by a turn to a social constructionist philosophy. We are not arguing that this is new since there is growing literature which advocates a constructionist pedagogy (Cunliffe, 2002, 2008; Dehler \& Welsh, 2014; Petligieri \& Petligieri, 2010). Yet in management education, such approaches continue to remain overshadowed by objectivist approaches (Berkovich, 2014; Raelin, 2009; Yanow, 2009) and as we shall see later, for students themselves, a constructionist approach was seen as both novel and challenging. A social constructionist position contends that our reality is constituted by the way in which we experience and understand the world and which we continually construct and reconstruct for ourselves in interaction with others (Berger \& Luckmann, 1966). It recognizes that social reality is emergent and precarious (Chia, 1995) and is inseparable from us: it is where "social realities and ourselves are intimately interwoven" (Cunliffe, 2008:124). Crucially, this stance also inevitably centralizes rather than displaces humanness since a precarious and socially constructed world foregrounds the frailties of our individual knowingness and emphasizes our social connectedness to other human beings. In sum, it is where:

"we are always a self-in-relation-to-others, living in, shaping and shaped by a web of relationship...[since]...we do not live in isolation..... we create our social and organizational realities with others in our everyday interactions and conversations (Cunliffe, 2009:95)

Insert Table 1 about here

In this scheme, our connections to others are centrally important as knowledge is generated through on-going dialogue with others. This for Yanow (2009) demands a humility which acknowledges the limitations of our individual knowingness and in turn, an openness and respect for others' views. Humility begins with a willingness to consider the possibility of 
error- that we might be wrong and requires "living with one's own possible anxieties induced by not knowing" (p.590). Yanow suggests that fundamentally this displaces 'a language of certainty' and instead, emphasizes a 'language of inquiry'. This further entails a "setting aside of one's ego, allowing someone else to share center stage" and "developing an otherregardingness"(p.590) where ultimately difference is seen "not so much as a threat to one's customary way of being but as potentially enlarging it" (p.595). Clearly, this also begins to point us to the notion of empathy and is especially relevant here in light of our analysis.

While recognizing that 'empathy' is a somewhat elusive and multifaceted concept encompassing cognitive and affective dimensions (Burch et al, 2016; Finn, 2009; Kerem, Fishman \& Josselson, 2001; Smith 2006), it is suggested that definitions which emphasize cognitive aspects which centre on perspective taking are particularly relevant to collaborative knowing in management. Indeed, Somogyi et al (2013) contend that it is the perspective taking aspects of the construct which are perhaps most relevant in a management context and, as we shall see, this is substantiated from our analysis of our management practitioners' accounts, presented shortly. Emphasizing such aspects, Hollin (1994: 1240 see Smith, 2006) for example, suggested that to display empathy is "the ability to see the world, including one's own behaviour, from another person's point of view". In this way, empathy does not necessarily involve sharing the feelings of another but may evoke a range of affective responses such as sympathy and tenderness (Batson \& Shaw, 1991; Kerem et al, 2001). Batson and Shaw (1991) contend that such affective reactions reflect a kind of emotional warmth and acceptance of the other. Critically then, empathy is manifest in self-other relations and is an interactionally accomplished phenomenon. As such it is recognized as a critical quality in the development of connectedness (Day, 2001; Hosking \& Fineman, 1990; Pavlovich \& Krahnke, 2012) where limitations between self and other are reduced, supporting a 'deeper awareness of self...within a coherent wholeness' (Liu \& Robertson, 
2010:3- see Pavlovich \& Krahnke, 2012). Taking this further, we argue that this development of connectedness holds particular promise for beginning to bring a sense of heart and soul back into management education.

\section{BRINGING THE HEART AND SOUL BACK IN}

To discuss notions of 'heart and soul' is not straightforward. We acknowledge the subtle and complex nature of these concepts and the allied prolific forms of religious and philosophical discussions and yet we need to remain focussed here on considering their specific constitution in management education. It is where the human/social connectedness to other human beings, potentially generated by collaborative knowing, provides one specific form of 'heart and soul'. It too rests upon humility and empathy as outlined earlier, and which evokes a sense of warmth and care towards others. As Waddock and Lozano (2013) contend "leaders with heart and soul recognize that no decision or action is taken alone" (p.267). This resonates with Lewin and Regine's (2000) discussion of engaging the soul at work, for them, 'soul' is to recognize people as people, connected to others via webs of relationships which also requires developing awareness of our impact on others and their effect on us. This consideration of self-other impact also brings in a particular notion of 'heart' which, in simple terms, involves "a more developed sense of social conscience that potentially embeds higher purpose or vision into businesses" (Waddock \& Lozano, 2013: 267). This inherently foregrounds a moral order (what is right and wrong, good and bad, just and unjust) which simultaneously also invokes and shapes a relational responsibility (Cunliffe, 2008). Consistent with Lewin and Regine (2000), ultimately, it is the power of our connectedness towards others which creates particular constructive future possibilities for organizations. The ways we engender this in management education are outlined next. 


\section{COLLABORATIVE INQUIRY IN MANAGEMENT EDUCATION}

Learning approaches which leverage our connections to others potentially offer particular promise for bringing our notion of heart and soul back into management education. Consistent with Yanow (2009), these approaches reposition "managerial expertise as mastery of mutual inquiry as much (if not more than) of subject matter knowledge" (p.591) and in doing so, accords legitimacy to others' local knowing. This re-positioning suggests the privileging of quite different concerns for management educators which move beyond a narrow focus on content knowledge and encourages a re-consideration of the faculty-student relationship. It invites a move beyond passive conceptualizations of learning which view the learner as an empty vessel to be filled with subject matter knowledge - transferred from faculty whose expertise is foregrounded (Armitage, 2010; Dehler \& Welsh, 2014; Raelin, 2009) - to embrace more dynamic and embodied notions of learning which view the learner and faculty as relationally embedded in an ongoing process of becoming (Petriglieri \& Petriglieri, 2010). As proposed by Freire (1998: 30), a shift is needed which recognizes that "to teach is not to transfer knowledge but to create the possibilities for the construction of knowledge". This move leverages the importance of classroom dialogue where students own experiences are recognized as equally important as faculty expertise, and hence is a stance which views faculty and students as 'partners' in a process of enquiry (Valentin, 2007) demanding a respect and dignity between tutors and students. Learning, then, is something that students and teachers do together and where knowledge is a product of the interactions between students and between student and teacher (Cunliffe, 2008; Gheradi, 2006; Reynolds, 1998). In sum, this move "engenders learning as a joint, collaborative (inquiry) process between tutor and student" (Armitage, 2010: 740).

Against this background, our article suggests that Van de Ven and Johnson's (2006) notion of 'engaged scholarship' which has collaborative inquiry at its centre offers educators one 
tangible starting point for centralizing our connectedness to others and thus bringing in a sense of heart and soul. To date, discussions of this framework have tended to focus exclusively on the research context and have overlooked how this might also be pertinent to the learning context. In so doing, collaborative inquiry has been considered in rather limited ways. This section, then, first outlines key facets of collaborative inquiry as originally developed for the research context by Van de Ven and Johnson (2006) before considering how these might also be relevant to the learning context and in particular to the DBA program with its focus on developing 'researching professionals'.

In Van de Ven and Johnson's (2006) notion of engaged scholarship, collaborative inquiry is where "academics and practitioners leverage their different perspectives and competencies to coproduce knowledge about a complex problem or phenomenon that exists under conditions of uncertainty found in the world" (p.803). It is underpinned by the concept of arbitrage: "a strategy of exploiting differences in the kinds of knowledge that scholars and practitioners can contribute to a problem of interest" (p.803). Hence, it is a dialectical form of inquiry. As such, constructive conflict management is also central to their scheme. This scheme is informed by a realist philosophy and one simple example illustrates this stance- it is where through the exploitation of multiple perspectives that "robust features of reality become salient" (p809). The authors add that the quality as well as impact of research improves substantially when researchers do four things: confront questions and anomalies existing in reality (again, resting on an assumption that the world is 'out there' waiting to be discovered); organize the research project as a collaborative learning community of scholars and practitioners with diverse perspectives where one or more members are relative insiders who study the issue over an extended duration; conduct research that systematically examines not only alternative models and theories but alternative practical formulations of the question 
of interest and, finally; frames the research and its findings to contribute knowledge to academic disciplines and to one or more domains of practice (p.815).

For Van de Ven and Johnson (2006) then, this type of inquiry creates impact through enhancing the type of knowledge that is produced: "it is more penetrating and insightful than knowledge produced when scholars or practitioners work on a problem alone" (p.815). They suggest it to be a form of inquiry which seeks to address the dual challenge of rigor and relevance of the research endeavour, and thus emphasize the academic researcher role. However, we suggest also that we need to consider collaborative inquiry as mobilized in a learning context which recognizes the often downplayed academic educator role (Bartunek \& Rynes, 2014). We argue that this opens up additional possibilities for collaborative inquiry and consequent forms of impact. As Antonacopoulou (2008; 2010) has argued, whilst we primarily focus on the relevance and rigor of our research we are at risk of neglecting the centrality of teaching and learning practices as an integral aspect of the impact that our scholarship delivers.

To contribute to this latter proposal, we suggest that DBA programs with their focus on developing 'researching professionals' provide one apposite learning site where our scholarship may be especially impactful and, importantly, in ways which enhances connectedness, potentially bringing in a sense of heart and soul as outlined earlier. To substantiate this claim, we draw upon our involvement with a particular UK DBA program. We first describe the key characteristics of this program before considering how this enlarges possibilities for collaborative inquiry. 


\section{THE DBA: PROGRAM DESCRIPTION AND BACKROUND}

DBA programs emerged in the UK in the 1990s and have grown steadily since (Bourner, Bowden, \& Laing, 2001). Banerjee and Morley (2013) observe that DBAs are offered by some $37 \%$ of UK universities. The DBA was one of a number of professional doctorates which developed in response to the perceived need to provide an alternative to the traditional $\mathrm{PhD}$ and to serve careers outside of academia (Bareham, Bourner, \& Stevens, 2000). Indeed, Bareham et al's (2000) analysis suggests that DBAs have been designed to provide researchbased career development for senior professionals in management. Typically, students will possess significant managerial experience as well as holding a relevant Masters qualification. In contrast to the $\mathrm{PhD}$ with its focus on developing 'professional researchers', DBA programs aim to develop 'researching professionals' (Bareham et al., 2000) and emphasize the enhancement of professional practice alongside developing knowledge contributions. As such, the development of the reflective practitioner is a common aim of many DBA programs (Sambrook \& Stewart, 2008).

The DBA is mostly offered through part-time delivery, completed over 3-6 years to enable students to continue to work full time (Bourner et al., 2000), and is classified as a research degree. While some variance is found, training in areas such as research design skills, research philosophy and methodology is provided alongside the appointment of a supervisory team. In addition, unlike traditional $\mathrm{PhD}$ programs, the cohort experience is often an integral feature of many UK DBA programs (Mellors-Bourne, Robinson \& Metcalfe, 2016) with formal structures such as action learning sets used to facilitate social support. Assessment usually occurs throughout the program via a number of specific documents with later documents assessed through a viva voce (Ruggeri-Stevens, Bareham, \& Bourner, 2001). Table 2 outlines the key features of the DBA under scrutiny here. 
Insert table 2 about here

The DBA program of focus here was developed in 1998 and now has over 150 graduates. It is a part-time program, which is usually completed in 3-4 years but can be extended up to eight years to accommodate varying circumstances. Students are highly experienced senior practitioners working in a variety of occupational areas across the globe. The DBA is structured around six documents which are submitted at spaced intervals over the duration of the program. The documents consist of a research proposal (5,000 words), literature review $(15,000$ words), two empirical studies, (one qualitative and one quantitative-each 15,000 words which serve as 'apprentice' pieces of research), and a final thesis (40,000 words, informed by the first four documents and utilizing a research approach of the students' own choice) together with a reflective piece on personal and professional development $(5,000$ words) which draws upon a diary which students are required to begin at the outset of the program. The first four documents are assessed internally and the final two documents are assessed externally via a viva voce examination.

Each of the documents is supported by a workshop of two to four days duration which is led by research active faculty who are themselves qualified to doctoral level. The entire cohort, typically around 10-15 students are invited to attend. The workshops are loosely structured and highly interactive where the delivered content stimulates student questions, comments and discussions in relation to their own areas of research. The experiences and perspectives of students are thus of key importance. The content provided relates to processes involved in the various stages of undertaking research allied to the six documents but is always informed by faculty's own experiences of undertaking research, with a particular emphasis on taking students 'behind the scenes' and sharing their own research struggles. In so doing, emphasis moves away from the transfer of faculty expertise to creating possibilities for the construction of knowing (Freire, 1998). The workshops also include numerous opportunities for informal 
conversations between faculty and students at lunch and coffee breaks. In addition to these workshops, students are allocated two academic supervisors and self-assign to a learning set comprising approximately 4-6 students usually dictated by geographical considerations. These learning sets meet in person while attending workshops and virtually, outside of the workshops to suit the demands of the set.

\section{Collaborative Inquiry and the DBA}

Consistent with the broad aims of DBA programs described above, the program aims to:

'develop practising managers as researchers who can make a contribution to knowledge that can inform judgement and practice of others whilst acquiring the ability to challenge both their own knowledge and assumptions as well as those of the organizations they work with' (DBA Program Handbook)

As we shall see, it is an aim mobilized in their practice and is one also consistent with key dimensions of collaborative inquiry outlined above by Van de Ven and Johnson (2006). However, important differences also exist since inquiry in this DBA context was fundamentally informed by a social construction philosophy. First, a central tenet is met whereby a contribution is framed in terms of theory and practice: students are expected to produce contributions to the knowledge-practice couplet. Second, given this dual focus, students are required to research their own practice/organizational based problems. Therefore, as recommended by Van de Ven and Johnson (2006) research problems and questions are firmly grounded in what they perceive as their 'concrete and observable phenomena' ( $\mathrm{p} 810)$, and importantly are often complex issues arising from conditions of uncertainty- what Grint (2005) has termed 'wicked problems'. In addition, these wicked problems are investigated over an extended period given that the DBA program takes several years to complete. However, unlike Van de Ven and Johnson (2006) who suggest longitudinal research which 
"provides repeated trials for approximating and understanding a research question or topic" (p.813) here, the problem itself is viewed as fluid- the nature of the issues to be investigated can themselves change over time thus recognizing the emergent nature of the phenomenon under investigation.

Third, from the outset of problem formulation, and consistent with Van de Ven and Johnson (2006), the research process is designed as a collaborative learning community. Here the DBA student takes the position of the relative insider in the research setting, and academic supervisors and fellow students are seen as relative outsiders who offer diverse perspectives on the research problem/phenomenon being investigated. While supervisors draw on relevant subject matter expertise to provide academic insights into the investigated problem, learning set members and members of the wider cohort in contrast hold diverse interests and as such may provide alternative insights which may be far removed from the problem area. Thus, a wider form of dialogical inquiry is engendered which invites contributions from a membership which extends beyond those closely involved with problem investigation. This moves us towards Valentin's (2007) proposal that faculty and students must be considered more in terms of partners in the learning process.

Fourth, related to the encouragement of sharing of diverse perspectives, the DBA program also crucially invites students to engage with alternative methodological positions and allied research methods. Indeed, as outlined above a key requirement of this program is that students undertake both a piece of quantitative/quasi-positivist and qualitative/interpretive piece of research. The motivation behind using these two philosophical-methodologies and multiple methods therein is not to 'distinguish robust features of reality' as suggested by Van de Ven and Johnson (2006 p809) - and hence, as if 'out there' - but instead as a means to challenge students own and 'other' assumptions and often, as we will shortly see, to engage with, and thus constitute their 'world' in different ways. 
In summary then, underpinning the DBA program here is a form of dialogical and collaborative inquiry which encourages students to interact with diverse perspectives. As we will shortly see, our analysis indicated that this form of inquiry created unforeseen forms of impact which resonated strongly with calls to develop a capacity for heart and soul in management education and to engender this in managers' everyday practice. We now outline our research approach before offering the analysis with a series of illustrations and our discussion to substantiate this central claim.

\section{METHODS}

\section{Empirical Materials and Research Participants}

We draw upon the experiences of students enrolled on the UK DBA program detailed above. Both authors have been heavily involved with teaching, supervision and examination on the program for many years and have repeatedly observed numerous examples of the deep impact the program had seemingly accomplished and in particular, as reported by students' reflective accounts submitted as part of their final program assessment. As supervisors and internal examiners, we were therefore aware of the richness of these final reflective accounts and hence, sought to systematically analyse these. We emailed 20 graduates of the program, selected at random, from three recent consecutive cohorts, to request permission for their reflective accounts to be used as part of our study. Our graduates are simply referred to by a student number later when offering our illustrative quotes in order to preserve the anonymity that was promised to them. Our sample was comprised of 18 males and 2 females from a variety of countries including the UK, USA, South Africa, and Greece. The students were all highly experienced practitioners holding a variety of senior management positions spanning private and public sector organizations, and can be broadly noted as being over 30 years of 
age. The composition of our sample reflects the student mix that we have typically found, and indeed, continue to find on our current program.

\section{Diary Method and its scope}

The final reflective account submitted for assessment 'rested' on a diary that students are expected to begin at the start of their DBA. Consistent with methodological understandings of diaries, a regular record of personal observations and experiences relating to their progress throughout their DBA studies is kept (Travers, 2011). Students are instructed to record events, thoughts and incidents that appear important to them and as close to the time that they occur as possible (Denzin, 1989). Further guidance from faculty is minimal. Hence, they maintain qualitative forms of diaries which are of an open and unstructured nature and which privilege their own words (Ohly, Sonnentag, Niessen, \& Zapf, 2010). At the end of the program, students review and draw on these diaries to produce the final critical reflection of their development. Indeed, they often reproduced quotes from their original diaries in their final reflective piece too. On one broad level then, such diaries can be seen to meet the interpretivist position which seeks "to understand the complex world of lived experience from the point of view of those who live it" (Schwandt, 1994: 118).

However, we also recognize that the use of such empirical material potentially raises a number of issues. First, while students' diaries record events as close to the time of occurrence as possible, they still report experiences after the event. Second, and as has been observed by others (Balogun, Sigismund, \& Johnson, 2003), DBA students were often initially uncomfortable in their role as diarists and which led to questions such as: how open and engaged were they in producing their accounts? Linked to this, we also acknowledge that students may inadvertently self-censor material. Clearly this is further complicated given that the final reflective piece is subject to formal assessment. Yet, our experience suggests that 
any initial discomfort faded as students became used to keeping a diary and we were often heartened by the level of self disclosure offered. Third, in the production of their final reflections, students select according to what they deem important at the end of the journey: this post-event rationalizing process may also potentially distort the account. However, while acknowledging these three issues and potential limitations, without doubt all the students' reflective pieces provided extremely rich material which they deemed important, leading to their selection of key moments of particular DBA experiences.

\section{Data Analysis}

Given our interest in privileging students' concerns, the research questions to which we have the answer arose from undertaking analysis first (Rawls, 2008). Our analysis was informed by Strauss and Corbin's (1998) grounded theory approach where themes emerged from our empirical materials. This meant that our analysis consisted of three key stages. However, these stages were not linear but, instead, consistent with Corley and Gioia (2004:183-184) formed a "recursive, process-oriented, analytic procedure (Locke, 1996: 240) that continued until we had a clear grasp of the emerging theoretical relationships". First, we began to familiarize ourselves with our data where we both independently read and re-read a small selection (six) of the students' reflective accounts with open minds to allow the data to speak to us (Suddaby, 2006). From doing so, we were struck by students' discussions of the development of forms of self and other awareness. We then began to utilize an open coding process to identify initial categories or first-order codes (Van Maanen, 1979) related to understanding the impact of DBA study as reported by students themselves, such as for example, perspective taking and patient consideration of others. Open coding then continued with an interest in tracing the ways in which such impact was deemed to have developed. For example, we began to notice the importance of interactions with others' on the DBA program as well as a recognition of the limitations of personal knowing. While undertaking this stage 
of the analysis, both researchers met regularly to discuss the emerging codes, with a focus on questioning the developing structure and making comparisons between student accounts. As we began to identify first-order codes, we used NVivo software to formalize and organize our analysis. Second, we then engaged in axial or pattern coding (Miles, Huberman \& Saldana, 2014; Strauss \& Corbin, 1998) which focused on looking for relationships between the firstorder codes which allowed us to assemble them into higher order themes, for example, collaborative inquiry, humility and openness, empathy, and connectedness. Once we had our initial codes and themes in place, we then turned to successive student accounts and analysed each of these in turn to extend and 'validate' or confirm our initial structure until we had reached a point of theoretical saturation, that is, where additional student accounts failed to add anything significantly to our current understanding (Strauss and Corbin, 1998). Third, as this analysis progressed we began to integrate our themes into overarching dimensions which when taken together, helped to deepen our understanding of the experiences of our students (Bansal \& Corley, 2012), and when combined with the themes identified in stage two, gave rise to our theoretical model presented shortly. An overview of our data structure is shown in Figure 1. While, as stated above, the analysis followed an iterative process throughout whereby themes emerging from the student accounts were compared against the literature (Alvesson \& Skoldberg, 2000), at this third stage, our key theoretical dimensions began to crystallize. What is important to note though, is that this process and our theorizing is also framed by what we bring to the empirical materials (Samra-Fredericks, 2010). For us, students' reports of their learning experiences resonated with Van de Ven and Johnson's (2006) notion of collaborative inquiry and yet this was insufficient to capture fully the complexity of the learning processes and impact that the students reported. For us, it was Yanow's (2009) ideas of mutual inquiry to which we had been earlier exposed, which helped us to understand how collaborative inquiry was enacted in the DBA context, and Waddock 
and Lozano's (2013) and Lewin and Regine's (2000) discussions of the heart and soul which allowed us to understand the impact it generated. Finally, as recommended by Strauss and Corbin (1998), we 'validated' our theoretical scheme by returning to each of our accounts to compare our scheme against our raw data. We now turn to a more detailed look at our analysis.

Insert Figure 1 around here

\section{FINDINGS}

\section{Overview}

The analysis of the students' accounts highlighted that the leveraging of diverse perspectives of academics and practitioners was a fundamental aspect of their studies and learning. Van de Ven and Johnson's (2006) notion of collaborative inquiry was thus seen in the DBA context. However, differences were found in how this was enacted and consequently, the impact generated as illustrated in Figure 2. First, collaborative inquiry developed a humility and openness in students through the displacement of what Yanow (2009) termed the language of certainty. Second, this humility and openness evoked a form of cognitive empathy (Smith, 2006) through a critical shift towards Yanow's language of inquiry where students respected and embraced difference and otherness. Third, this empathy generated a connectedness to others (Pavlovich \& Krahnke, 2012) and from their self-reports of connectedness, we argue that they also began to bring in a sense of heart and soul. It was - and remains - an unexpected and deeper form of impact of collaborative inquiry in this context. In sum, we suggest that the underlying processes of the displacement of a language of certainty and the promotion of a language of inquiry add insights into how collaborative inquiry is mobilized in the DBA context to create possibilities for bringing the heart and soul back in. We now elaborate on this set of broad analytical points 
Insert Figure 2 around here

\section{The Displacement of a Language of Certainty}

The accounts consistently highlighted that an engagement with others had begun to soften previously held certitudes. There was then an evident displacement of a language of certainty which began to create a space for a move towards a language of inquiry which we discuss shortly (Yanow, 2009). More specifically, here, three central forms of interaction with others, often described by students themselves as 'critical incidents' were reported to trigger this shift interwoven with, and constituted through, the emerging use of a language of inquiry: interaction with faculty; interaction with research participants and interaction with fellow students. First, then, their accounts reported an engagement with faculty perspectives which leveraged contrasting philosophical research positions were especially salient and is concisely illustrated by the student below:

"The DBA program exposes the student to a number of ontological and epistemological perspectives.... It is perhaps this... in terms of professional development that is taken from the program the most. The fundamental challenges that this has presented in terms of values, understandings, habits and practices are far reaching." [Student, 11]

This is just one glimpse of the ways in which engagement with different philosophical perspectives, allied to the program's requirement to undertake both a piece of quantitative and qualitative research worked to fundamentally challenge understandings and hence unsettle previously accepted certainties. The analysis suggested that in particular, discussions of qualitative and interpretive perspectives - central to their third piece of assessed work were especially important in displacing certainties:

"After the completion of the third Document, I began to realize the nature and logic of the DBA process; I had realized that Economics is not the only science, not the only way of 
interpreting reality. As a result, my approach has shifted from the "world of macro and micro economics" to the world of the DBA perspective: the DBA (especially qualitative analysis) has made me see things from the human perspective, to realize managers' fears, feelings and worries about the future of their enterprises." [Student 6]

While faculty delivering this workshop could have easily avoided daring students to move beyond their 'comfort zones', as the quote above illustrates, for many students while challenging them, it also provided a new way of seeing the world. Perhaps unsurprisingly, time and time again, the students seemed to initially view the world through an exclusively quasi-positivist/realist lens where 'things'/problems were 'out there' and/or could be measured or taken as stable 'facts'. Exposure to, and conversations with faculty to persuade them to consider the contrasting interpretive perspective inherently also made such facets far more unstable. Different methodological perspectives, then, did not instrumentally distinguish 'robust features of reality' (Van de Ven \& Johnson, 2006) but challenged understandings of what was taken as reality itself as we further elaborate shortly. In addition, as the above quote indicates, this also began to elevate limitations of our individual knowingness: here, the student acknowledges "fears, feelings and worries" indicative of a less certain form of knowing. Interestingly, though, there is also an element of learning-throughdistancing evident in this quote: A shift from ' $\mathrm{I}$ ', 'my' and 'me' to the more generalized 'managers' fears' - perhaps suggestive of work still underway. In contrast, for others, the analysis highlighted that engagement with the interpretivist perspective offered by faculty in the third workshop enabled them to explicitly acknowledge the limitations of their personal knowing and indeed, was described as one of the most salient aspects of the DBA:

"I found it an enriching experience using grounded theory to immerse myself in the subject without any particular hypothesis and to allow the theory to form around me. It was also liberating to know that I was no longer looking for the one 'right' answer - whatever 
conclusion I reached would be valid as it represented my interpretation of the information available even if it was different from a finding that someone else would have made...I found [this workshop] one of the most stimulating and personally developmental parts of the program." [Student 1]

This is one example of the ways in which their engagement with a particular form of analysis associated with the interpretive perspective enabled the student to recognize that one's perspective is but one of a number of possible ways of viewing a situation and that others may hold diverse but equally valid perspectives. It is another small glimpse of Yanow's (2009) call for a displacement of a language of certainty and arguably it is also an initial step towards developing humility since the importance of the self-perspective is challenged and potentially displaced. Yet, this 'partial knowing' was also seen as 'liberating' since the weight of expectation to be 'right' was mitigated.

The analysis also identified that alongside these kinds of interactions with wider faculty in the workshops, conversations with supervisors were reported to further underline students' partial knowing, as is shown in the next example:

"Whenever, I thought that doing research on diversity would be easy and clear-cut, my supervisors challenged me to dig deeper and elaborate on concepts more than I had, and in doing so, issues of my own bias came to light. I say the biggest part of my growth throughout the DBA program, has been a result of my two advisors... They were right most of the time, so this helped me be able to push my ego aside and listen to them." [Student 7]

It was apparent that the supervisors' perspectives brought to the research phenomena being investigated, here diversity, disrupted previous ways of seeing and highlighted gaps in the student's understanding. Student engagement with academic perspectives which typically involved a certain depth and precision, developed an enlarged understanding of the research 
problem and in so doing, the student begins to recognize the value of knowing with others, again illustrating a growing humility where the 'ego is pushed aside'.

Second, our analysis found that engaging with the perspectives of their own research participants, notably the interviewees that the students' interacted with during their empirical pieces of assessed work, also constituted this recognition of their partial knowing and thus, a growing sense of humility:

"I discovered that an explanation does not only have one location, one perspective, one reality. There were multiple perspectives and multiple realities, and the positioning of the interviewee cannot be limited. I found that, as a consequence, I was limited by my experience and knowledge. I realized that, if I had excluded the possibility of diverse responses and looked for confirmation of previously held notions, knowledge would not have been advanced.”[Student 13]

As this quote illustrates, taking seriously the views of interviewees- often in their own organization- led to a recognition of multiple ways of seeing without which understanding would be restricted. The next example further highlights the ways in which interviewees' perspectives were reported to enlarge understanding by raising questions around earlier views, here, those developed during MBA study:

"During the interviews, I realized in practice that it is quite difficult to implement the theoretical "good practices" that I used to learn at the MBA level, especially in a sector whose role has died away. It can be argued that these "good practices" sound effective but the ideal conditions to implement them cannot easily exist. ...In general, through this process, I have learned to be more patient and "eavesdrop" carefully on experienced people [my supervisors, professors or businessmen].” [Student, 6] 
Interactions with interviewees then ostensibly added a complexity to students' understandings and did so in ways where the limits of knowing alone were acknowledged. Instead, the ways in which we know together begins to be valued and foregrounded- a sense which is further illustrated below:

"Power...was a new concept for me as I had previously thought that, if anything, the interviewee held the balance of power in that they could refuse the interview and perhaps slant the interview to enhance perceptions of themselves. Naively, I had never thought that I might impose my worldview on a subsequent interpretation." [Student 9]

For this student, a consideration of interviewee perspectives stimulated a recognition of the ways in which these were simultaneously shaped by her own perspectives. This form of emergent understanding was again found to unsettle previous certainties and from doing so, there also emerged a developing sensitivity towards the self-in-relation-to-others, and hence an impact on those others which we discuss shortly. Third, the analysis revealed that engagement with the perspectives of other cohort members was also critical in diminishing previously held certainties and in ways which appeared to begin to enable students to develop an awareness of the self-in-relation-to others. We quote at length from Student 7 to convey the criss-crossing of dialectical work and the role of the other:

"Having the opportunity to see how others handle issues of discrimination, has allowed me to reconsider my own biases such as understanding that everything is not as black and white as I had previously believed, instead my experiences lead me to believe that maybe it's an understanding issue.....Doing the research into diversity, I never thought or even looked at myself to be part of the problem. Even when (name of fellow student) and I talked about Kandola's book, I would always question her, how could minorities be part of the problem and have biases, but she was right, and Kandola was right too. In order for social 
organizations to move forwards with diversity, everyone has to first eliminate their own biases. This research helped to eliminate many of the biases that I still carried around with me over the years, by presenting new challenges to me at every turn." [Student 7]

Again, this is just one illustration of the wider forms of involvement with others' perspectives- who unlike in Van de Ven and Johnson's (2006) scheme- have no vested interest in problem solution. It is through dialogue with wider cohort members, as seen in the example here that the student came to acknowledge his own biases. The analysis also identified that an important aspect of these discussions with fellow students which worked to unsettle previous certainties, was that they offered a 'safe' space to further engage with the faculty perspectives introduced in workshops and supervisory interactions:

"The early discussions on methodological perspectives [with cohort members] opened my mind to different ways of thinking. Initially, I found terminology and concepts difficult and would test my understanding through discussion with 'trusted' colleagues with whom I knew I could safely make mistakes." [Student 2]

Discussions of these 'difficult' perspectives with 'trusted' cohort members allowed these views to be seriously considered, creating 'different ways of thinking'. Both of these examples begin to illustrate the ways in which students were then inevitably drawn towards an openness to engaged learning with others.

In sum, these three forms of interaction with others- faculty, research participants and fellow students - 'triggered' a displacement of prior certainties and elevated a far more precarious view of the world. This also fosters a growing awareness of the limitations of our individual knowingness and hence, a form of humility emerges. This then seemed to initiate a complex re-positioning of the self and others as inseparable from the issue of inquiry. Further, as we 
have begun to glimpse above and as shall be further elaborated below, this also encouraged an openness to dialogue with others.

\section{A Shift Towards a Language of Inquiry}

The students' accounts also consistently reported that their interactions with others invited a crucial re-consideration of difference and otherness which were now seen to enlarge rather than impede understanding (Yanow, 2009). As the next two illustrative quotes show, an openness to knowing with others had come to be welcomed and valued, and was, we suggest, indicative of a shift towards Yanow's (2009) language of inquiry:

"I have learned many things from the experiences of my classmates, they are people from different countries with different backgrounds and pictures. In this way, they presented different approaches on an issue that I had not thought of before...As a person, this process has absolutely changed me: now, I have learned to listen first and talk afterwards. I have also become more patient and less selfish. I have certified that other people (students with different backgrounds) can have interesting views and different approaches on a certain issue." [Student 6]

"Being a part of an Action Learning Set [and a Cohort], helped to develop my listening and questioning skills. It also helped me to give and accept feedback. These are essential skills needed for leadership in the field of [practice]." [Student 19]

The examples concisely illustrate a regard for others and an embracing of their differences. The first quote conveys a new found respect for others' local knowing which is prioritized ahead of personal views. As such, we inherently also glimpse a movement of the self away from 'center stage' and instead an openness to knowing with others. The second quote again denotes that through student interactions (both with the action learning set and the wider 
cohort), a valuing of knowing together emerged, and where listening to others was emphasized alongside an ability to inquire. Simply, in this way an inherent connectedness to others as we come to know our world is engendered too. While we are aware that these could be idealized accounts, the students themselves did go on to offer details to situate their claims, as we will see later too. This growing recognition of others and the valuing of difference also created possibilities which extended into their everyday management practice. We begin to glimpse this in the second quote above and in this next quote too:

"Another effort that I am doing is to widen and deepen conversations. As an example of this effort, we today invite people with different backgrounds from within our organizations but also from outside them, to listen to their ideas and opinions which allow us to create a more complex view of reality." [Student 4]

This begins to illustrate the ways in which a language of inquiry comes to be enacted in this manager's everyday practice. Here, is now a deliberate effort to invite and listen to diverse perspectives from other areas of the organization and indeed, beyond. Such steps also begin to engender forms of cognitive empathy since it rests on the ability to take the position of the other (Hollin, 1994, see Smith, 2006), as well as inherently rendering a more 'complex view of reality': Clearly, this is often a difficult undertaking, as the student continues to elaborate below:

"When someone has a completely different perspective I try to understand what cues he noticed and what he discovered through them. Today, I am also able to look at conflicts as opportunities for sensemaking instead of making an effort to suppress them, as I used to do in the past." [Student 4]

As this example shows, to take the position of the other again requires that difference is reconsidered. Consistent with Van de Ven and Johnson's (2006) notion of arbitrage, this student 
notes the value in constructively managing conflicts of difference so that opportunities for new ways of seeing are provided. We too also begin to see the ways such learning was inherently linked to faculty's role in terms of exposing students to different theoretical perspectives. Specifically here, for example, we see referral to 'cues he noticed' and 'sensemaking' and this explicitly points to Weick's (1995) perspective to which these students had been exposed as part of their third module with its focus on interpretive perspectives. In sum, this is just one small illustration of a different kind of engagement with others: in saying 'I try to understand what cues he noticed and what he discovered through them' there is also a sense of an initial crucial step towards empathy. This growing ability to take the position of the other is further illustrated by the student below:

"I used to consider these jobs were relatively easy; however, I realized how difficult it is to fight for survival when competition is hard. After the conduct of these [interview based] studies, I have learned to appreciate the efforts of people working in these places [referral to sectoral context]. I always take notice and respect the hard efforts of managers/owners of these enterprises that are trying to ensure the day's labor." [Student 6].

It was through conversations with others, here, with interview participants that the students were better able to see from the point of view of the other. In other words, to display empathy (Hollin, 1994, see Smith, 2006). For this particular student, it engendered a respect and understanding of the other in-situ which, as we shall see next, provided opportunities for enhanced connectedness to others as well as suggesting deeper forms of impact emerging from collaborative inquiry when mobilized in a learning context.

\section{Creating Impact: Bringing in the Heart and Soul}

Our analysis of student accounts highlighted that collaborative inquiry created impact which extended far beyond the creation of more robust forms of research knowledge (Van de Ven \& 
Johnson, 2006). Instead it enhanced a connectedness to others which we propose opened up possibilities for more heartfelt and soulful management practice. Critically, as has been glimpsed in many of the illustrative quotes reproduced so far, engaging with difference on the DBA program evoked a form of empathy where the perspective of the other was embraced and efforts to understand it emerged. As we shall see next too, and consistent with others such as Pavlovich and Krahnke (2012), the students reported that this generated a sense of enhanced connectedness to others, one constituted by a growing sense of the self-in-relationto-the-other where the impact of the self on others and others on the self was acknowledged (Lewin \& Regine, 2000). Notably, this seemingly evoked an affective response of warmth and care towards others and in ways which simultaneously expanded future horizons for the self and others.

To convey this and the ways students' accounts consistently reported different forms of engagement and connection to others in their everyday management practice, the following two quotes are reproduced to concisely illustrate this facet:

"Overall, I became a more informed practitioner and evolved from a sales person whom simply marketed his firm's offering towards being a consultative sales professional. Indeed, I now rely on research and knowledge to elaborate solutions that are specific to each client." [Student, 15]

This student reports a more 'consultative' style of practice which entailed consideration of distinctive individual needs underlining a different form of engagement and re-connection to others. A care towards the other is implicitly evoked through this consideration of the specific needs of the other. Other accounts similarly described a growing connectedness to others in their everyday practice where others views were more carefully considered as this next 
illustrative quote conveys. We reproduce it at length since it also concisely conveys something of the complexity and scope of impact engendered:

"If I had to choose the most important thing I learned through this experience, it would be the improvement of my capacity to deal with uncertainty. Throughout my professional life, I lived difficult situations, both in terms of complex environment contexts and in terms of complicated relationships between shareholders and management teams. I retrospectively recognize that, on several occasions, I had limited capacity to address and learn from these experiences in the most effective way basically because I adopted a defensive attitude and because of that, I did not have the openness to understand that others had a different reading of the circumstances.... Thus, I must be able to discover solutions out of contradictions in terms of adjustment to different cultures, mindsets and challenges. In order to do this, when I am not sure about what path to adopt, I tried to be attentive to new ideas and thoughts instead of rushing into action. This is difficult because some of my colleagues consider this attitude as an expression of incapacity to take action. Thus, to keep options open for some time requires not only capacity to tolerate ambiguity but also capacity to live with the pressure from my colleagues." [Student 4]

This student reports a growing sense of the self-in-relation-to-the-other- both in terms of considering others' views and the impact that doing so generated for others. What was especially interesting here was the recognition of the increased time that was needed to seriously consider others' views and that this potentially necessitated a period of inaction which then brought further challenges. While there is often a backgrounded and typified view of managers, here we see the ways it can surface along with subtle consequences: In this instance it is where managers must take quick and decisive action but which were now being skilfully challenged through a new and embodied form of practice with conscious efforts not to give in to a diffuse form of pressure from the other. Indeed, there is also a noted 'growing 
'capacity' to deal with the uncertainty that engaging with difference evokes. As Yanow (2009) suggested, setting aside one's ego and being open to diverse views requires that we also live with the anxiety that is inevitably produced. So, here, we also see that important emotional aspect of learning from collaborative inquiry being concisely captured. As the next quote further illustrates too, this re-connection and careful consideration of the other opened up alternative future possibilities for self and others:

"When I started on my [DBA] journey, my work was about getting [the unemployed] into self-employment. I now realize that it is so much more than that. It is also about opening their eyes to the fact that that they can learn; they don't have to see themselves as society's rejects. They are capable. They need to set themselves their own goals and not let others around them sculpt their lives for them." [Student 19]

As an illustrative glimpse of a re-connection to the organizational client- here, the unemployed - there is a move from seeing them as 'society's rejects' to 'capable' human beings which again brings to our attention an awareness of the self-in-relation to the otherand crucially, the ways in which individual views' shape possibilities for others. Furthermore, it clearly and inherently evokes a moral responsibility (Cunliffe, 2008) and care towards fellow human beings. Clients are now seen in a more empowered and inclusive way which then potentially expands future horizons for them. We suggest that it is in such subtle but critically important ways that they bring a sense of the heart and soul into their everyday practice. The student below further illustrates this:

"As a student who has experienced a diversity of alternative ideas I have begun to develop a more global viewpoint and be able to consider different aspects of a problem. Now I see that ethical thinking is neither a matter of pure intellect nor of gut feelings and prejudices. What is important here is one's reasoning and critical thinking skills. Thus, by strengthening and 
expanding these skills, I have been able to view our ever-changing policy world from a new perspective, and not be limited by the past or previous belief-systems....I now understand my decision making to [include questions such as] who are the stakeholders in the decision? What consequences [if any] do you see your decision has on others involved?" [Student 17]

As another brief glimpse of the ways in which exposure to different perspectives on the DBA encouraged a different type of connection to others during everyday practice - here, this particular student now seeks to more explicitly consider others in decision making. Questions such as who should be included in decision making processes and the likely impact of any decision on others are attended to. Again, we propose this connectedness subtly brings in a sense of heart and soul and evokes a care towards others. This more inclusive and careful consideration works to expand future horizons for the self and others affected by policy decisions since, as we begin to discern here, they are not limited by past and present ways of doing.

Notably for some too, this care towards others also moved beyond the organizational context, to expand horizons for family members. Hence, the impact of collaborative inquiry extended well beyond immediate organizational problem resolution:

"My competence in constructing compelling arguments, of understanding different perspectives and the realization that the world is a social construction of those who inhabit it have genuinely moved me to a different intellectual plane from where I began the Doctorate....A defining moment came for me during a session on philosophy within one of the [workshops]. The tutor was toying with us, teasing and challenging us...after lively debate the suggestion was laid bare how constrained our thinking had been-in many cases for our whole lives up to this point.... The power of the moment remains with me as a father 
of two young children, I now consciously try not to contract their world and to continuously challenge and debate with them to keep their minds alive with possibilities." [Student 1]

We witness here a father's specific form of care for his children as he worked to expand 'their minds [through keeping them] alive with possibilities', just as he too seems to have experienced during a DBA workshop. This example powerfully illustrates the ways in which engagement with faculty and fellow students on the program, two of the key triggers outlined earlier, were generative of deeper forms of connection with others and in ways which expanded future horizons.

Also of importance for sustained impact in their management/professional and personal domains of practice, the accounts identified an ongoing humility and openness which continued to acknowledge students' partial knowing. This is concisely articulated by the following two illustrative quotes:

"When I make an error or face conflict and lack of success, it is not a reason for defensiveness but, instead, a signal that I have something more to learn. " [Student 13]

"However, despite the slightly giddy feeling of relief and exultation, as I near the end of this particular stage of my journey, the DBA has taught me a sense of personal and intellectual humility and acute awareness of the fact that my personal learning journey is actually far from over. " [Student 8]

Highlighting the iterative nature of collaborative inquiry depicted in figure 2 , both quotes capture something of the humility developed during the DBA program, which nurtured open and curious individuals who continued to ask questions of themselves, well beyond the completion of their studies. In so doing, we argue that they begin to shift away from elevating rational/instrumental forms of analysis and decision making to acknowledging complexity 
and not-knowing, thereby foregrounding human frailties often neglected in management education (Petriglieri \& Petriglieri, 2015). Of importance, it is others who can potentially fill in the gaps. The accounts, either implicitly or often more explicitly, identified a concern to cultivate ongoing opportunities to (re)-connect with others. That they also required particular capabilities to do so is concisely summed up in the next two illustrative student quotes:

"There is only one thing I can do about this. That is to have courage and trust. To join a learning set of like-minded individuals about evidence based management or just management. To engage often and maybe aim to be the positive one. There is a real danger that my lethargy makes the group lethargic, so I resolve to be the project core not the periphery. This should be more dangerous, more fun and in opening up my skills and opinions to greater and regular scrutiny, the quality of my work should improve too. I realize that working with others is a start on the way to achieving my true potential." [Student 17]

"I have mentioned the massive impact of friendship and teamwork, but it bears repeating now. Teamwork is not the sum of its parts but a massive multiplier on the components. Whilst in this course I have learned and developed a number of objective tools and methodologies, I have also recognized again that using them to drive teamwork generates far more power than anything I can deliver as even the most dedicated executive”. [Student 5]

These illustrations highlight the importance given to ongoing mutual inquiry (Yanow, 2009) as well as conveying a sense of attachment and warmth towards others engendering an affective response. Again, we argue that this gives promise for bringing in a sense of heart and soul since, as outlined earlier, "leaders with heart and soul recognize that no decision or action is taken alone" (Waddock \& Lozano, 2013). This underlines our inherent social connectedness to other human beings in ways which create opportunities for a more considerate and inclusive practice. Yet, we are also not so naïve as to 'read off' from these 
accounts a simple 'move' to humanize practice. As others have noted too (Sambrook \& Willmott, 2014) and which we also hope to have conveyed - this move continued to be a challenge and often, at the close of their reflective piece as the quote above from Student 8 indicated, there was a recognition that their journey was not over and remained full of possibilities for the future.

\section{DISCUSSION}

This article has sought to respond to recent calls for how we might bring the heart and soul back into management education. Through embracing a supplementary form of knowingwhat Van de Ven and Johnson (2006) term collaborative inquiry- we have one important starting point for educators. We have suggested that collaborative inquiry, when mobilized in a DBA program context, centralizes a way of knowing our world through our interactions with others which evokes a connectedness to these others and in so doing, creates promise for a more heartfelt and soulful practice. Crucially, our interactions with others displace our prior certainties or taken for granted understandings and invite a pause for that moment to 'learn' where a humility and openness to the other then emerges. In turn, through the critical shift to a language of inquiry which pivots on valuing difference and otherness, the perspective of another is taken, developing a form of empathy (Smith, 2006, Somogyi et al 2013). Significantly, for us, this empathy promotes a social connectedness to other human beings (Pavlovich \& Krahnke, 2012) which brings in a specific form of heart and soul. It is where, as suggested by Waddock and Lozano (2013), individuals realize that no decision or action is taken alone, and where the impact of the self on others and others on the self is acknowledged (Lewin \& Regine, 2000) often then evoking a sense of warmth and care towards the other.

Our research sought to offer two related contributions. First, we have extended Van de Ven and Johnson's (2006) conceptualization of collaborative inquiry through a consideration of 
how this is mobilized in a learning context. For Van de Ven and Johnson (2006) in a research context, collaborative inquiry utilizes multiple perspectives as a means to develop the rigor and relevance of knowledge. Fundamentally, it is a stance which is informed by an evolutionary realist philosophy which assumes that there is an objective, independent and fixed reality waiting to be discovered and "by exploiting multiple perspectives (of others), the robust features of reality become salient" ( $\mathrm{p} 809$ ). This conceptualization thus positions the individual as a potentially mechanical instrument which stands outside of the inquiry process and others as objects to be manipulated. It is thus an instrumental inquiry which emphasizes a form of distance and separateness. In contrast, as outlined in figure 2 , in our DBA learning context, collaborative inquiry worked to encourage engagement with multiple perspectives of others to develop the individual-in-relation-to others. This was informed by a social constructionist philosophy which posits that our reality is subjective, constructed through social interaction, and is emergent. Here, the multiple perspectives of diverse others including faculty, fellow students and their own research participants acted as complex and elusive triggers which unsettled what was to be taken as reality and leveraged the limitations of individual knowing, engendering humility and openness. Consistent with Yanow (2009), a language of certainty was displaced and replaced with a language of inquiry where listening to others first and tolerating the ensuing anxiety of not knowing were foregrounded. The individual was thus embodied in the ongoing and mutual process of inquiry and indeed, becomes 'other' through this process (Chia, 1995). Critically, then, others were positioned as persons to be engaged with. For educators, this may appear rather unremarkable, yet for students, as we hope to have illustrated here, this was especially significant.

Our second related contribution outlines how, as described by students themselves, this type of collaborative inquiry generated forms of impact which extended beyond acquisition and exploitation of subject matter knowledge. As our analysis sought to convey and concisely 
illustrate, here, the leveraging of multiple perspectives cultivated a form of empathy where the student was better able to see the world from another's point of view (Hollin, 1994, see Smith 2006). Consistent with other studies which have examined empathy from the perspective of those who experience it (Kremen et al., 2001), in our management learning context, cognitive aspects of the construct were therefore especially salient. Yet while students did not necessarily share the feelings of others, the empathy described here often generated affective responses towards the other. Crucially, invoking this empathetic ability generated an enhanced sense of our human/social connection to other human beings, and hence for us, a specific notion of heart and soul where the impact of the self on others and others on the self was acknowledged (Lewine \& Regine, 2000) evoking a warmth and care towards the other. This connectedness we suggest offers promise for a more inclusive and considerate form of management practice which expands and broadens horizons for the self and others. Potentially too, this provides for a more effective practice since the impact of decisions on others becomes integral to what is decided. Here, we hope to have conveyed some sense of the warm, attached and open human beings who outlined in their own words their efforts to engender ongoing care for their practice-in-relation-to-others: It stands in contrast to those cold, detached and closed analysts thought to be the product of other forms of management education (Leavitt, 1989).

More broadly too, our work adds to discussions of a wider notion of impact. First, impact can include a contribution to the individual and forms of collective growth, providing empirical support for Antonacopoulou (2016). Furthermore, given our analysis, for some, we add impact on family too. Second, this impact is far from trivial and reinforces calls to include our teaching practices as integral to the impact of our scholarship (Antonacopoulou, 2010, Tushman, O'Reilly, Fenollosa, Kleinbaum, \& McGrath, 2007). Indeed, this is especially apposite in the DBA context given the influential positions DBA students typically hold. 
Third, our work underlines the importance of calls to understand impact from the point of view of those who experience it (Aguinis, Shapiro, Antonacopoulou, \& Cummings, 2014; Bartunek \& Rynes, 2014) - here, the student practitioners through their own accounts of their learning journey. This permits deeper and perhaps unexpected forms of value to be gleaned which might otherwise be overlooked and which we hoped to have captured and conveyed here.

\section{Implications for Educators}

While recognizing that our work is located in a particular DBA context, these findings have broader generalizability or transferability to other management education programs. First, given our interpretivist stance, it is important to highlight that when we, as individuals, read such research accounts then elements of this transferability criterion are routinely brought into 'play' and assessed too - questions such as, does this echo my experiences? How does my educational context differ from this and in that light, would such initiatives bring similar outcomes? And so on and so forth. Furthermore, our stance embraces generalizability of a different kind and which was concisely summed up by Watson (1994:7, also citing Yin, 1984) in light of his ethnographic study of one organization: it is where such qualitative studies offer a means of 'generalizing about processes members get involved in and/or about basic organizational activities, rather than about 'all managers' or 'all organizations' and as such, it is a matter of generalizing 'theoretically' rather than 'empirically'. With this focus on processes in mind, we suggest a number of conditions which, if in place, may allow others to usefully employ elements of our collaborative inquiry approach. First, we suggest the importance of engaging with students who have significant organizational experience to ensure that the practice perspective is developed and opportunities are readily available for research in-situ. Second, engaging with students over long periods is also necessary to allow space for the kinds of learning reported here to emerge. Third, it is crucial that the cohort 
experience is leveraged given that student interactions were of special importance here. Further, we also suggest that smaller class sizes of around 10-15 students are key to facilitating student interaction since they provide a safe space for students to discuss issues with trusted others. Fourth, we suggest the salience of the inclusion of research projects given the value of working with methodological perspectives for our students.

A number of programs may meet such conditions. Most obviously, our findings may be applicable to other similar DBA programs as well as $\mathrm{PhD}$ programs where the cohort experience is leveraged and students are experienced practitioners, or are undertaking research where they are deeply engaged in the organizational context, such as for example, where ethnographic and action research approaches are used. In addition, our findings may have applicability beyond doctoral programs to Masters level programs. For example, like the DBA program reported here, executive MBA programs are also focused on senior level practitioners and are often delivered on a part-time basis over a relatively prolonged period of time (typically around two years), are expected to leverage the cohort experience, and often involve a research dissertation (Mintzberg, 2004). Where these conditions exist, educators might attempt to mobilize the following three elements of our program that have been identified as central triggers in displacing a language of certainty to create a space for a movement towards a language of inquiry. As outlined above, this shift is crucial to creating possibilities to re-engage hearts and souls in management education.

First, we have suggested that interactions with faculty were central triggers to the displacement of a language of certainty. Arguably, the most crucial element of these interactions focused on discussions of multiple methodological perspectives which were necessary given the program's requirement to undertake both a piece of qualitative and quantitative research- and as we hope to have conveyed above - often constituted changed ways of seeing the world and understandings of the individual's position within it. We 
suggest the advantages of faculty sharing their own research and making explicit their own underlying philosophical positions and in ways which foreground their own research struggles, as one means for students to engage with these diverse perspectives so crucial to displacing their prior certitudes. For example, during one workshop activity the second author shares short extracts of her own raw empirical materials in the form of transcribed strips of real time interaction and invites students to offer their own interpretations of the data. In so doing, the frailties of our individual knowingness come to be foregrounded as well as inherently opening up new ways of conceptualizing and understanding our worlds.

Second, we have also identified the importance of the mobilization of these methodological perspectives through students' interactions with their research participants, often in their own organizations. We suggest that other programs therefore might also benefit from encouraging students to seriously engage with different methodological perspectives and their allied research methods. While, undertaking apprentice projects allied to contrasting perspectives might not always be possible within the time constraints of other programs, some engagement with different methodological perspectives might go at least some way to further unsettling previous ways of seeing. For example, we propose the value of students utilizing different research methods to engage with organizational members whose views may previously have been left relatively unexplored as one way of beginning to illustrate the limitations of personal knowing and which also inherently complexifies 'reality'. This kind of engagement, however, was not without challenges for students since it would initially prove deeply unsettling and anxiety provoking, especially given the senior status of the practitioner students here. Yet we would argue that this kind of unsettling is integral to the learning we have described here and it is for educators to identify ways in which students can be better supported to recognize and work through these emotions (cf Locke, Golden-Bidlle, \& Feldman, 2008). For us, having regular contact with students over an extended period of time, 
including during workshops, and through sharing our own research anxieties, enabled students to trust us, to open up and share their own anxieties and thus learn.

Third, we also suggest that fostering interactions between students provides a further important means for working with these emergent emotions as well as unsettling prior understandings. It is critical then that opportunities for student dialogue are leveraged. We would suggest the importance of less structured approaches in the classroom which avoid a rigid reliance on slide presentations as one way of encouraging student interactions. For example, in our program's workshops we often use forms of peer assessment (Stribjbos \& Sluijsmans, 2010) where students are encouraged to provide feedback on each other's work, such as a poster session where students present their conceptual frameworks for their research projects and invite constructive comments from their peers. This allows students ideas to be opened up to question and encourages additional perspectives which can enhance their conceptual thinking, and in doing so, this again reinforces the value in knowing with others. In addition, the use of action learning sets can progress and sustain conversations beyond formal classroom time with trusted others alongside the use of journaling which provides a further space for students to wrestle with new perspectives. Journaling (upon which this article is based) allows students to critically reflect on their learning, and to make sense of that learning through the process of writing itself too (Richardson, 1997). We also recognize that leveraging student perspectives can produce anxiety for educators themselves (Vince, 2010) and educators are then challenged to develop their own openness towards, and engagement with student views. This also then opens up possibilities for faculty to learn too, as we have done ourselves. For example, engaging with practitioner perspectives in workshops often forced us to develop ways in which our research could be made more accessible to practitioner audiences. 


\section{Future Research}

In terms of future research directions, we would first highlight that while we have made the case for the transferability of our research findings above, as Lincoln and Guba (1985) remind us, whether findings 'hold in some other context, or even in the same context at some other time, is an empirical issue" (p316). Hence, for us, it remains important to outline specific opportunities for future research in order to expand and deepen our understanding of collaborative inquiry in other settings. Do similar outcomes emerge to the ones described here when collaborative inquiry is used in other contexts? For example, what outcomes might emerge where executive MBA programs encourage students to engage with alternative methodological positions and their allied research methods? Future research might also examine the ways in which students' work contexts may inform and support their learning (or not). Also, are there differences between sectors and different geographical areas? Equally, research might seek to identify additional ways in which students can be supported in dealing with the inevitable emotions generated by collaborative inquiry as well as, for example, providing more detailed understandings of the role of action learning sets in other contexts. Our work has focused on the students' views of collaborative inquiry; future work may also turn to providing insights into faculty's perspectives when engaging in this approach. What challenges arise and what learning occurs for faculty too? Perhaps more ambitiously, as one of the authors has done so in an allied field of study (Samra-Fredericks, 2003), future research might also seek to follow individuals beyond the classroom into their everyday practice. This would then allow us to uncover more nuanced understandings of the kinds of connectedness reported here but also the ways practitioners can or cannot expose their heart and soul as they do their everyday work, in situ. As Sambrook (2008: 69) comments, a key question is whether such learning can be sustained 'in performance driven organizations'. 


\section{CONCLUSION}

At a time when the form and impact of management education continues to be questioned, our article has sought to offer an example of an approach which highlights the difference we can make as educators. Here, we have empirically illustrated how collaborative inquiry (Van de Ven \& Johnson, 2006) when mobilized in the context of a DBA program with highly experienced senior practitioners, fostered a humility and openness to knowing with-andthrough others. This developed a form of empathy which evoked our human connectedness to these others, and ultimately, in so doing, it begins to bring in a sense of one's heart and soul thought to be neglected in management education. More importantly this impact was identified as salient by practitioners themselves through their reflective accounts of their DBA learning. It seemingly surprised them, given their often articulated rational goals, and it surprised and heartened us too. As educators, it continues to teach us to be humble and open to the student perspective and thus to learn from, with, and for, each other. 


\section{REFERENCES}

Aguinis, H., Shapiro, D. L., Antonacopoulou, E. P., \& Cummings, T. G. 2014. Scholarly impact: A pluralist conceptualization. Academy of Management Learning \& Education, 13: 623-639.

Alvesson, M. \& Skoldberg, K. 2000. Reflexive Methodology. London: Sage.

Antonacopoulou, E.P. 2016. Realizing Y-our impact: the return to reflexivity to rediscover paideia and the purpose of management. Paper presented at the EURAM Conference, Paris, $1^{\text {st }}-4^{\text {th }}$ June.

Antonacopoulou, E.P. 2010 Making the Business School More 'Critical': Reflexive Critique based on Phronesis as a Foundation for Impact. British Journal of Management, 21: 6-25.

Antonacopoulou, E.P. 2008. Mastering Business Action: Implications for Management Learning in Business Schools. In M. Bild, P. Märtesson \& K. Nilsson (Eds.), Teaching and Learning at Business Schools: 279-293. Gower: Hampshire.

Armitage, A 2010. From sentimentalism towards a critical HRD pedagogy. Journal of European Industrial Training, 34 (8/9): 735-752.

Balogun J., Sigismund, A. \& Johnson P. 2003 Three responses to the methodological challenges of studying strategizing. Journal of Management Studies, 40: 197-224.

Banerjee, S. \& Morley, C. 2013. Professional doctorates in management: Toward a practicebased approach to doctoral education. Academy of Management Learning \& Education, 12: 173-193.

Bansal, P. \& Corley, K. 2012. What's different about qualitative research? Academy of Management Journal, 55: 509-513. 
Bareham J., Bourner, T. \& Stevens G.R. 2000. The DBA: What is it for? Career Development International, 5:394-403.

Bartunek, J.M. \& Rynes, S.L. 2014. Academics and practitioners are alike and unlike the paradoxes of academic-practitioner relationships. Journal of Management, 40: 1181-1201.

Batson, C.D. \& Shaw, L.L. 1991. Evidence for altruism: Toward a pluralism of prosocial motives. Psychological Inquiry, 2: 107-122.

Bennis, W.G. \& O' Toole, J. 2005. How business schools lost their way. Harvard Business Review, 83: 96-104.

Berger, P. \& Luckmann, T. 1966. The social construction of knowledge: A treatise in the sociology of knowledge. Open Road Media: Soho, NY, USA.

Berkovich, I. 2014. Between person and person: Dialogical pedagogy in authentic leadership development. Academy of Management Learning \& Education, 13: 245-264.

Bourner, T., Bowden, R. \& Laing, S. 2001. Professional doctorates in England. Studies in Higher Education, 26: 65-83.

Brocklehurst, M., Sturdy, A., Winstanley, D. \& Driver, M. 2007 'Introduction: Whither the MBA? Factions, Fault Lines and the Future. Management Learning, 38: 379-388.

Burch, G. F., Bennett, A. A., Humphrey, R. H., Batchelor, J. H., \& Cairo, A. H. 2016. Unravelling the complexities of empathy research: A multi-level model of empathy in organizations. In Ashkanasy, N., Hartel, C.E.J. \& Zerke, W.J. (Eds.), Emotions and Organizational Governance (pp. 169-189). Emerald Group Publishing Limited.

Chia, R. \& Holt, R. 2008. The nature of knowledge in business schools. Academy of Management Learning \& Education, 7: 471-486. 
Chia, R., 1995. From modern to postmodern organizational analysis. Organization Studies, 16: 579-604.

Corley, K.G. \& Gioia, D.A. 2004. Identity ambiguity and change in the wake of a corporate spin-off. Administrative Science Quarterly, 49: 173-208.

Cunliffe, A.L. 2009. The philosopher leader: On relationalism, ethics and reflexivity-a critical perspective to teaching leadership. Management Learning, 40: 87-101.

Cunliffe, A.L. 2008. Orientations to social constructionism: Relationally responsive social constructionism and its implications for knowledge and learning. Management Learning, 39: 123-139.

Cunliffe, A.L. 2002. Reflexive dialogical practice in management learning. Management Learning, 33: 35-61.

Datar, S. M., Garvin, D. A., \& Cullen, P. G. 2011. Rethinking the MBA: Business education at a crossroads. Journal of Management Development, 30: 451-462.

Day, D.V. 2001. Leadership development: a review in context. Leadership Quarterly, 11: 581-613.

Dehler, G.H. \& Welsh, M.A. 2014. Against Spoon-Feeding For Learning. Reflections on Students' Claims to Knowledge. Journal of Management Education, 38: 875-893.

Denzin N.K. 1989. The Research Act: A Theoretical Introduction to Sociological Methods. Englewood Cliffs, NJ: Prentice Hall.

Finn, S.E. 2009. The many faces of empathy in experiential, person-centred, collaborative assessment. Journal of Personality Assessment, 9 (1): 20-23.

Freire, P 1998. Pedagogy of Freedom. Oxford: Rowan and Littlefield. 
Gherardi, S. 2006 Organizational Knowledge: The Texture of Workplace Learning. Oxford: Blackwell.

Ghoshal, S. 2005. Bad management theories are destroying good management practices. Academy of Management Learning \& Education, 4: 75-91.

Grint, K. 2005. Problems, problems, problems: The social construction of 'leadership'. Human Relations, 58: 1467-1494.

Holtom, B. \& Dierforff, E. 2013. Disrupt or be disrupted: A blueprint for change in management education. Hoboken, NJ: Wiley and Sons.

Hosking, D. \& Fineman, S. 1990. Organizing processes. Journal of Management Studies, 27 (6): 583-604.

Irgens, E. J. 2014. Art, science and the challenge of management education. Scandinavian Journal of Management, 30: 86-94.

Kerem, E., Fishman, N. \& Josselson, R. 2001. The experience of empathy in everyday relationships: Cognitive and affective elements. Journal of Social and Personal Relationships, 18 (5):709-729.

Khurana, R. 2010. From higher aims to hired hands: The social transformation of American business schools and the unfulfilled promise of management as a profession. Princeton University Press.

Leavitt, H.J. 1989. Educating our MBAs: On teaching what we haven't taught. California Management Review, 31: 38-50.

Lewin, R. \& Regine, B. 2000. The Soul at Work. New York: Simon \& Schuster. 
Lincoln, Y.S. \& Guba, E.G. 1985. Naturalistic Inquiry. Beverly Hills, CA: Sage.

Locke, K., Golden-Biddle, K. \& Feldman, M. 2008. Making doubt generative: Rethinking the role of doubt in the research process. Organization Science, 19: 907-918.

Mellors-Bourne, R., Robinson, C. \& Metcalfe, J. 2016. Provision of Professional Doctorates in English HE institutions. Cambridge: Careers Research and Advisory Centre.

Miles, M.B., Huberman, A.M. \& Saldana, J. 2014. Qualitative Data Analysis. A Methods Sourcebook, $3^{\text {rd }}$ Edition. Thousand Oaks: Sage.

Mintzberg, H. 2004. Managers, not MBAs: A hard look at the soft practice of managing and management development. Berrett-Koehler Publishers.

Nonaka, I., Chia, R., Holt, R. \& Peltokorpi, V. 2014. Wisdom, management and organization. Management Learning, 45: 365-376.

Ohly, S., Sonnentag, S., Niessen, C. \& Zapf, D. 2010 Diary studies in organizational research. An introduction and some practical recommendations. Journal of Personnel Psychology, 9: 79-93.

Pavlovich, K. \& Krahnke, K. 2012. Empathy, connectedness and organization. Journal of Business Ethics, (105): 131-137.

Petriglieri, G. \& Petriglieri, J. L. 2015. Can Business Schools Humanize Leadership? Academy of Management Learning \& Education, 14: 625-647.

Petriglieri, G. \& Petriglieri, J.L. 2010. Identity workspaces: The case of business schools. Academy of Management Learning \& Education, 9: 44-60. 
Pfeffer, J. \& Fong, C.T. 2002. The end of business schools? Less success than meets the eye. Academy of Management Learning \& Education, 1: 78-95.

Raelin, J.A. 2009. The practice turn-away: Forty years of spoon-feeding in management education. Management Learning, 40: 401-410.

Rawls, A. 2008. 'Harold Garfinkel. Ethnomethodology and workplace studies'. Organization Studies 29:701-732.

Reynolds, M. 1998. Reflection and critical reflection in management learning. Management Learning, 29: 183-200.

Richardson, L. 1997. Fields of Play: Constructing an Academic Life. New Brunswick, NJ: Rutgers University Press.

Ruggeri-Stevens G., Bareham J. \& Bourner T. 2001. The DBA in British Universities: assessment and standards. Quality Assurance in Education 9: 61-71.

Saggurthi, S. \& Thakur, M. 2016. Usefulness of uselessness: a case for negative capability in management. Academy of Management Learning \& Education, 15: 180-193.

Sambrook, S. (2008). Critical HRD: A concept analysis. Personnel Review, 38(1): 61-73.

Sambrook, S., \& Willmott, H. 2014. The rigor of management education and the relevance of human resource development: Natural partners or uneasy bedfellows in management practice? Management Learning, 45: 39-56.

Sambrook, S. \& Stewart, J. 2008. Developing critical reflection in professional focused doctorates: a facilitator's perspective. Journal of European Industrial Training 32: 359373. 
Samra-Fredericks, D. 2010. Where is the 'I'? One silence in strategy research. Advances in Strategic Management Research, 27: 411-444.

Samra-Fredericks, D. 2003. Strategizing as lived experience and strategists' everyday efforts to shape strategic direction. Journal of Management Studies 40(1): 141-174.

Schwandt, T.A. 1994. Constructivist, interpretivist approaches to human inquiry. In: Denzin NK and Lincoln YS (eds) Handbook of Qualitative Research. Thousand Oaks, CA: Sage, 118-137.

Somogyi, R.L., Buchko, A.A. \& Buchko, K.J. 2013. Managing with empathy: Can you feel what I feel? Journal of Organizational Psychology, 13 (1/2): 32-42.

Smith, A. 2006. Cognitive and emotional empathy in human behaviour and evolution. Psychological Record, 56 (1): 3-21.

Starkey, K., Hatchuel, A. \& Tempest, S. 2004. Rethinking the Business School. Journal of Management Studies, 41: 1521-1531.

Strauss, A. \& Corbin, J. 1998. Basics of Qualitative Research. Techniques and Procedures for Developing Grounded Theory, $2^{\text {nd }}$ Edition. London: Sage.

Strijbos J.W. and Sluijsmans, D. 2010. "Unravelling peer assessment: Methodological, functional and conceptual developments", Learning and Instruction, 20: 265-269.

Suddaby, R. 2006. From the editors: What grounded theory is not. Academy of Management Journal, 49: 633-642.

Travers, C. 2011. Unveiling a reflective diary methodology for exploring lived experiences of stress and coping. Journal of Vocational Behavior, 79: 204-216. 
Tushman, M. L., O'Reilly, C., Fenollosa, A., Kleinbaum, A. M., \& McGrath, D. 2007. Relevance and rigor: Executive education as a lever in shaping practice and research. Academy of Management Learning \& Education, 6: 345-362.

Valentin, C. 2007. Researching human resource development: emergence of a critical approach to HRD enquiry. International Journal of Training and Development, 10: 17-29.

Van de Ven, A.H. \& Johnson, P.E. 2006. Knowledge for theory and practice. Academy of Management Review, 31: 802-821.

Van Maanen, J. 1979. Reclaiming qualitative methods for organizational research: A preface. Administrative Science Quarterly, 24:520-526.

Vince, R. 2010. Anxiety, politics and critical management education. British Journal of Management, 21: s26-s39.

Waddock, S. \& Lozano, J.M. 2013. Developing more holistic management education: Lessons learned from two programs. Academy of Management Learning \& Education, 12: $265-284$.

Watson, T.J. 1994. In Search of Management. Culture, Chaos and Control in Managerial Work. London: Routledge.

Weick, K.E. 1995. Sensemaking in Organizations. London: Sage.

Yanow, D. 2009. Ways of knowing. Passionate humility and reflective practice in research and management. The American Review of Public Administration, 39: 579-601. 
TABLE 1

Detached Knowing v Collaborative Knowing

Detached Knowing

Realist philosophy

Objective and fixed reality

Analytical methods \& procedures

Solitary and independent

Technical-rational expertise

Language of certainty

Expertise as all knowing

Dispassionate and cold: Displaces human characteristics

Closure

\section{Collaborative Knowing}

Social constructionist philosophy

Subjective and emergent reality

Dialogical inquiry

With others and interdependent

Local expertise

Language of inquiry

Accepts limits of our knowingness

Passionate and warm: Centralizes human characteristics

Openness

Sources: adapted from Chia \& Holt, 2008; Yanow, 2009 
TABLE 2

\section{Characteristics of UK DBA Program of focus here}

\begin{tabular}{|c|c|}
\hline Characteristics & DBA Program \\
\hline Background & $\begin{array}{l}\text { Developed in } 1998 \text { with aim to develop the 'researching } \\
\text { professional' capable of critically reflecting on their practice. }\end{array}$ \\
\hline \multirow[t]{4}{*}{ Structure } & $\begin{array}{l}3-4 \text { years part time programme with flexibility to extend up to } 8 \\
\text { years. }\end{array}$ \\
\hline & $\begin{array}{l}7 \text { workshops broadly aligned to } 6 \text { assessed documents (see } \\
\text { assessment below) each lasting 2-4 days, delivered in the UK. }\end{array}$ \\
\hline & 2 academic supervisors allocated to each student \\
\hline & Learning sets of between $4-6$ students \\
\hline
\end{tabular}

10-15 students per cohort

Students are highly experienced senior practitioners who also hold a Masters level qualification.

Males and females; working in a variety of occupational areas, diverse international base including China, Malaysia, Nigeria, Portugal, United Arab Emirates, USA, and UK.

\begin{tabular}{lll}
\hline Assessment Structure & Research Proposal & 5,000 words \\
& Literature Review & 15,000 words \\
& Qualitative empirical piece & 15,000 words \\
& Quantitative empirical piece & 15,000 words \\
Thesis & 40,000 words \\
Reflective journal & 5,000 words
\end{tabular}




\section{Figure 1: Data Structure}

First order codes

\begin{tabular}{|c|}
\hline $\begin{array}{l}\text { - Interactions with faculty } \\
\text { - Interactions with students } \\
\text { - Interactions with research } \\
\text { participants }\end{array}$ \\
\hline $\begin{array}{l}\text { - Acknowledging limitations of } \\
\text { personal knowing } \\
\text { - } \quad \text { Questioning } \\
\text { - Complexity of reality }\end{array}$ \\
\hline
\end{tabular}

- Respect \& regard of others

- Embracing different views

- Prioritizing listening to others

- Perspective taking

- Self-other awareness

- Expansion of future horizons for self \& others

- Patient consideration of others

- Warmth and care towards others

\section{Second order themes}

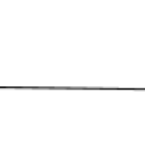

Collaborative Inquiry

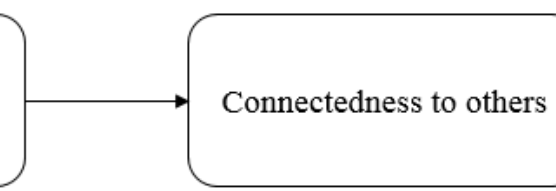

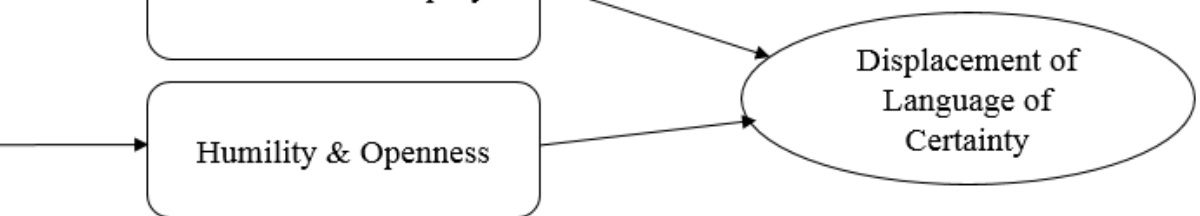

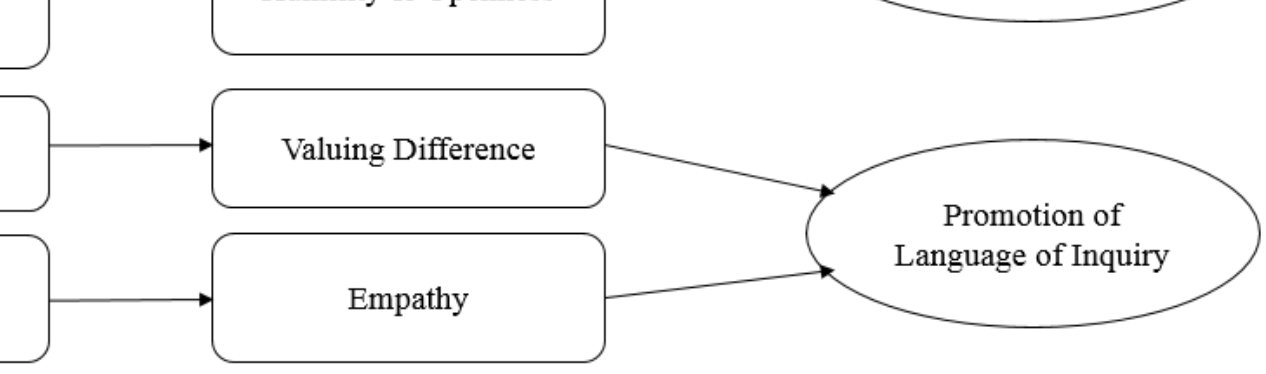

Promotion of Dimensions

Displacement of anguage of

Certainty

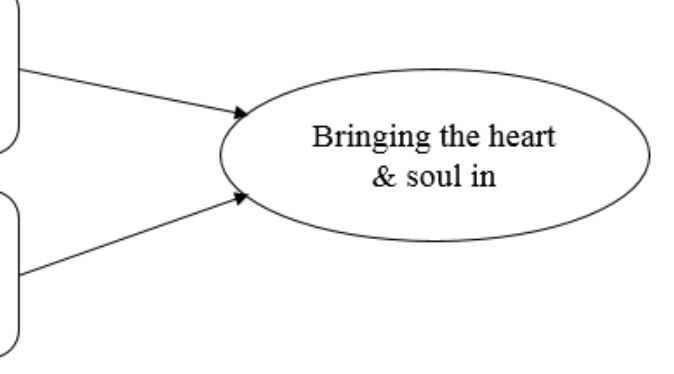


Figure 2: Collaborative Inquiry in Management Education

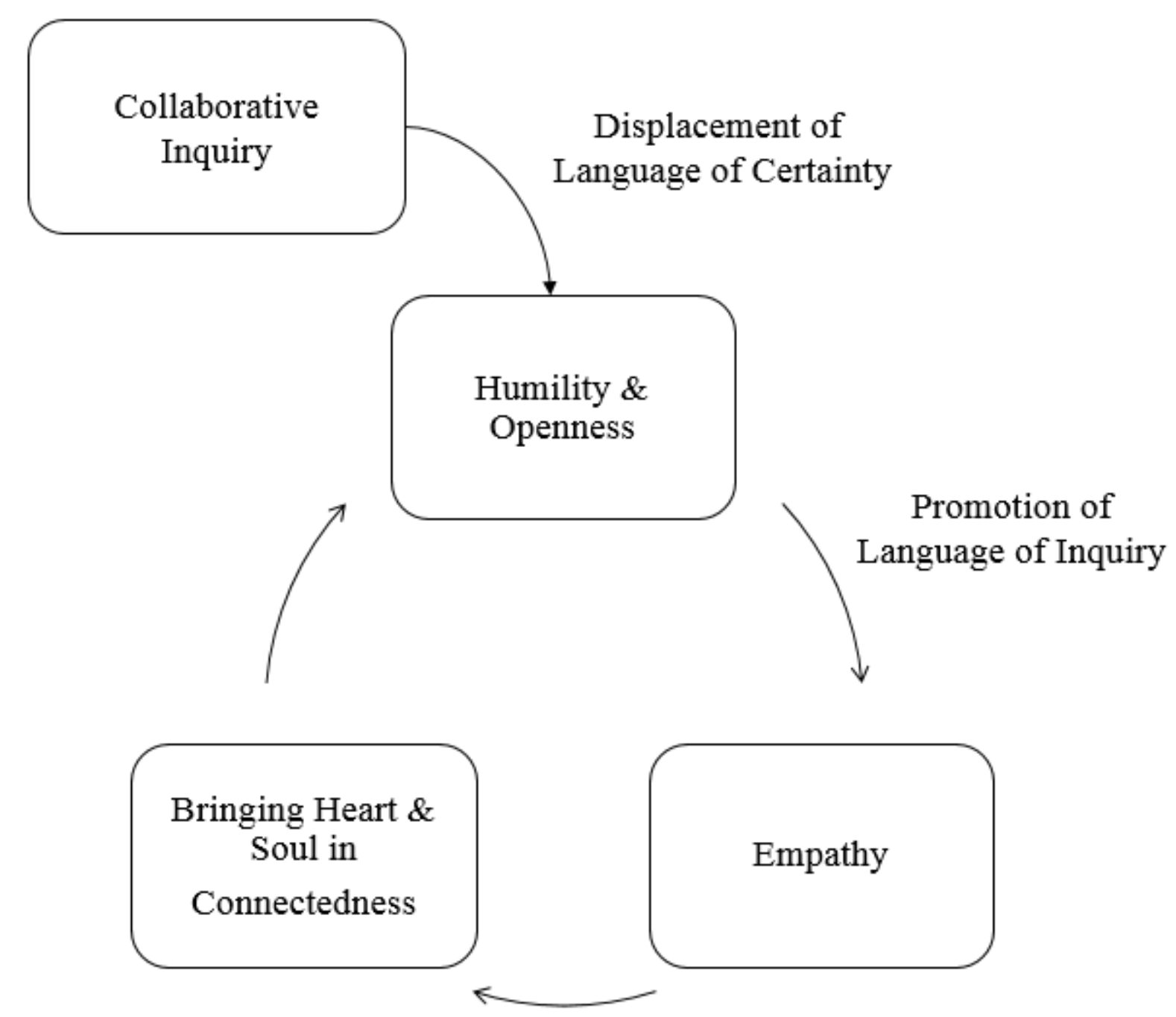


